\title{
Letter
}

\section{Response to Comment by A. RICHTER, M. HORWATH, R. DIETRICH (2016) on 'Mass gains of the Antarctic ice sheet exceed losses' by H. J. Zwally and others (2015)}

\section{SUMMARY}

Richter, Howarth and Dietrich (2016) and their Russian colleagues have made very precise geodetic measurements on Vostok Subglacial Lake using GPS (and GLONASS) in situ measurements. They use those measurements to estimate the rate of change of the height of the ice-surface $\left(\mathrm{d} H_{\text {surface }}\right.$ $\mathrm{d} t$, or $\mathrm{d} h_{\mathrm{gps}} / \mathrm{d} t$ in our notation) over the Lake, concluding that the surface height has been stable at a rate close to zero (e.g. $\mathrm{d} h_{\mathrm{gps}} / \mathrm{d} t=+0.3 \pm 4.9 \mathrm{~mm} \mathrm{a}^{-1}$ in Richter and others (2008) and $\mathrm{d} h_{\mathrm{gps}} / \mathrm{d} t=+1 \pm 5 \mathrm{~mm} \mathrm{a}^{-1}$ in Richter and others (2014)). That conclusion differs from our findings of an average rate of $+20 \mathrm{~mm} \mathrm{a}^{-1}$ over the Lake, as derived from two independent satellite altimetry measurements (ERS-1/ERS-2 and ICESat) over $17 \mathrm{a}$.

The objective of geodetic measurements with markers in the firn is to estimate a relatively small rate (e.g. $10 \mathrm{~mm}$ $\mathrm{a}^{-1}$ ) of surface motion to an accuracy of a few $\mathrm{mm} \mathrm{a}^{-1}$ as the difference of two larger rates (e.g. $-62.1 \mathrm{~mm} \mathrm{a}^{-1}$ marker velocity and $72 \mathrm{~mm} \mathrm{a}^{-1}$ new snow growth), where the uncertainty in snow growth is large for reasons we described. Our finding of a variation of $\mathrm{d} h / \mathrm{d} t$ from $<0$ to $>30 \mathrm{~mm} \mathrm{a}^{-1}$ over the Lake from ICESat data indicates how important taking account of the spatial variability is to achieve valid comparisons with the satellite data. We also believe that the vertical strain rate in the compressing firn and the emplacement of the geodetic markers requires more attention. The lack of a discernable systematic reduction in $\mathrm{d} h / \mathrm{d} t$ at the transitions from the grounded ice to the ice over the Lake or in the central area (certainly not in a ratio of $8 \%$ ) raises fundamental questions about the concept of hydrostatic equilibrium as applied to the analysis of 'floating' of ice on Lake Vostok. Overall, we believe that the uncertainties in the geodetic measurements are sufficiently large that the in situ measurements and our altimetry measurements are not necessarily inconsistent.

\section{DISCUSSION OF MEASUREMENTS}

1.'Richter and others (2014) present results of....kinematic GNSS profiling...repeated in 2012 and 2013. In 308 crossovers, ... a mean...of... $1 \pm 5 \mathrm{~mm} \mathrm{a}^{-1}$ was determined,....'

We did not address that measurement, but note that the profiling was over an area of a strong northeast to southwest gradient in $\mathrm{d} H_{\text {surface }} / \mathrm{d} t$ with values ranging from $<-40 \mathrm{~mm}$ $\mathrm{a}^{-1}$ on the northeast to $>+40 \mathrm{~mm} \mathrm{a}^{-1}$ on the southwest. Their RMS of $\mathrm{d} H_{\text {surface }} / \mathrm{d} t$ from 308 out of 837 total crossovers differences is $\pm 15 \mathrm{~mm} \mathrm{a}^{-1}$ (inappropriately labeled std dev.). They say: 'This leads to a formal accuracy of... $1 \mathrm{~mm} \mathrm{a}^{-1}$ ', which presumably is the sigma of the mean assuming a Gaussian distribution of a random variable. However, their $\mathrm{d} H_{\text {surface }} / \mathrm{d} t$ are systematically distributed over a strong gradient in $\mathrm{d} H_{\text {surface }} / \mathrm{d} t$ around the station, likely due to the influence of the station on upwind and downwind snow drift.
Therefore, their '....Allowing for a certain correlation,.... $5 \mathrm{~mm} \mathrm{a}^{-1}$ would be a realistic accuracy estimate' does not provide a proper error estimate. In contrast, their larger RMS of $\pm 15 \mathrm{~mm} \mathrm{a}^{-1}$ is an indication of the systematic variation of $\mathrm{d} H_{\text {surface }} / \mathrm{d} t$ that is very similar to the systematic variations of the ICESat measured $\mathrm{d} h / \mathrm{d} t$ over the entire Lake, which are also strongly influenced by drifting snow over surface undulations (our Fig. 5).

Although not randomly distributed, the shape of the distribution of $\mathrm{d} H / \mathrm{d} t$ in their Fig. 3b appears to be near Gaussian with outliers in the tails and a small positive mean for the central part. We performed a convergent 3-sigma edit on the distribution that eliminated nine outliers in the bins at -50 , $-45,-40$, and $+50 \mathrm{~mm}$, giving a mean of $+2.5 \mathrm{~mm} \mathrm{a}^{-1}$ and a median of $+5 \mathrm{~mm} \mathrm{a}^{-1}$, both of which suggest a small elevation increase with a RMS variability of $\pm 15 \mathrm{~mm} \mathrm{a}^{-1}$.

2. 'Richter and others (2014) discuss in detail, the fact that the ice sheet above Subglacial Lake Vostok is in hydrostatic equilibrium......the local surface height change observed at a point...reflects primarily the mean ice-thickness change over the lake area. Spatial variations in the ice-thickness change are attenuated by a factor $\left(\rho_{w}-\rho_{i}\right) / \rho_{w}$ (with water density $\rho_{w}$ and ice density $\left.\rho_{i}\right)$, thus propagating only $8 \%$ of the difference between the local and the mean ice-thickness change to the surface height. In the light of the hydrostatic balance, the significant spatial variation in height change rates across the lake area in Fig. 5 of Zwally and others (2015),...need(s) further explanation.'

Two definitive findings from the ICESat measurements as shown in Fig. 5 are: (1) a significant spatial variability of $\mathrm{d} h / \mathrm{d} t$ over the Lake surface from $<0$ to $>30 \mathrm{~mm} \mathrm{a}^{-1}$; and (2) a strong similarity of the $d h / d t$ over the Lake surface with the $\mathrm{d} h / \mathrm{d} t$ over the surrounding grounded ice. There clearly is no systematic reduction in $\mathrm{d} h / \mathrm{d} t$ at the transitions from the grounded ice to the ice over the Lake or in the central area, certainly not in a ratio of $8 \%$.

We believe that our findings provide new information about the behavior of the ice over the Lake and the subglacial hydrology that calls for additional scientific investigation, and perhaps reevaluation of what is meant by floating ice and hydrostatic equilibrium as applied to Vostok Lake. It seems there is a fundamental difference between a lighterthan-water solid (e.g. an iceberg) floating in water of sufficient depth that the solid does not touch bottom, and ice 'floating' on a layer of water of lesser depth where the inflow and outflow is constrained. Another example of the latter would be a steel piston 'floating' in a lubricated cylinder above a smaller thickness of oil, which is also a situation of hydrostatic equilibrium with a balance of pressures at the steel/oil interface. If the flow of the underlying fluid is not constrained, then the fluid flows out (hydrodynamics) and the solid falls to the bottom, as in the numerous Antarctic subglacial lakes (e.g. Wingham and others, 2006; Fricker and Scambos, 2009) that are only hydrostatic when not in state of draining or filling. We also note that the ratio of our observed rates of height change $\left(\sim 20 \mathrm{~mm} \mathrm{a}^{-1}\right)$ to ice thickness are extremely small (i.e. $<1 / 10^{5} \mathrm{a}^{-1}$ ) so that deviations from hydrostatic conditions or the rates of change in the subglacial water exchange 
could be very small and not be observable in features of the topological analysis in their referenced papers that concluded a state of hydrostatic equilibrium.

3. 'Zwally and others (2015) misinterpret Fig. 4 of Richter and others (2014) writing: "Similarly, $\Delta H i$ (i.e. $\Delta H(t i)$ in Fig. 4 of Richter and others, 2014) mostly overlap rather than separate in time as they would if bias adjustments were applied." This figure is intended to reveal surface deformations instead of height changes over time. Therefore, any effect of inter-campaign biases is eliminated beforehand...'

We meant that our equivalent $\Delta H(t i)$ plots using our bias adjustments do separate in time. Theirs do not separate, presumably because their bias adjustments were determined over the Lake assuming the surface elevation was not "changing".

4. 'Richter and others (2008) document the accumulation rates and snow densities observed in-situ around Vostok station. These are challenged....and...(their) statement "Richter and others (2008)...did not actually measure the rise of the snow surface in the vicinity of their GPS markers" is not true. ..... Instrumental accumulation monitoring (e.g. in arrays of accumulation stakes) is usually too limited....to account rigorously for the spatial component of snow build-up variation. A pragmatic approach to reduce the noise introduced by this spatial variation is to increase the temporal integration interval. For this reason, and considering the significant 50 a period in temporal accumulation variation established in the Vostok station area (Ekaykin and others 2004), Richter and others (2008) preferred the 200 a mean accumulation rate over that derived from 25 a of stake measurements.

Our analysis correctly stated that Richter and others (2008) estimated new snow growth at the GPS marker using a 200 a mean accumulation rate from an ice core and a snow density 'of $0.33 \mathrm{~g} \mathrm{~cm}^{-3}$ ' as 'the best estimate for the surface snow layer...from numerous snow pits and....accumulation stake farm', and that they did not use contemporaneous new snow growth measured at the markers.

Our principal point was that estimates of new snow growth are very sensitive to the choice of accumulation rate, which has both significant spatial and temporal variability. 'The density value of $0.33 \mathrm{~g} \mathrm{~cm}^{-3}$.... was used to derive the accumulation rate of $22.9 \pm 1.8 \mathrm{~mm} \mathrm{a}^{-1}$ from the snow build-up observed in the Vostok stake farm in the period 1970-1995....and there is neither reason nor evidence given by Zwally and others (2015) for why a density of $0.30 \mathrm{~g} \mathrm{~cm}^{-3}$ is "a better value" for the Vostok station area.' The relevant density needed to estimate the new snow growth above a GPS marker, along with accumulation rate $A$, is the density near the snow surface $\left(\rho_{n s}\right)$. Our alternate value of $0.30 \mathrm{~g} \mathrm{~cm}^{-3}$ is from density measurements at Dome Fuji in EA (Takahashi and Kameda, 2007). Nevertheless, if Richter and others' had actually used that 'stake-farm' accumulation rate of $22.9 \mathrm{~mm} \mathrm{a}^{-1}$ (instead of the $20.6 \mathrm{~mm} \mathrm{a}^{-1}$ from their 200 a mean) along with their density of $0.33 \mathrm{~g} \mathrm{~cm}^{-3}$, their estimate of the new snow growth would have been $69.4 \mathrm{~mm} \mathrm{a}^{-1}$ instead of $62.4 \mathrm{~mm} \mathrm{a}^{-1}$, and along with their GPS measurement of $-62.1 \mathrm{~mm} \mathrm{a}^{-1}$ their estimate of $\mathrm{d} H_{\text {surface }} / \mathrm{d} t$ would then have been $7.3 \mathrm{~mm} \mathrm{a}^{-1}$ instead of their $0.3 \pm 5.0 \mathrm{~mm} \mathrm{a}^{-1}$. In either the case of $\mathrm{d} H_{\text {surface }} / \mathrm{d} t$ equal to $+7.3 \mathrm{~mm} \mathrm{a}^{-1}$ or our calculation of $14.2 \mathrm{~mm} \mathrm{a}^{-1}$ using $\rho_{\mathrm{ns}}$ equal to $0.30 \mathrm{~g} \mathrm{~cm}^{-3}$, our conclusions regarding the sensitivity of the snow growth to accumulation and their underestimate of the error in their $\mathrm{d} H_{\text {surface }} / \mathrm{d} t$ of $0.3 \pm 5 \mathrm{~mm} \mathrm{a}^{-1}$ remain valid.
We noted that larger 'values of $A$ in the range $24-30 \mathrm{~mm}$ $\mathrm{a}^{-1}$ are also supported by the $17 \mathrm{ka}$ means along transects west of the lake derived from radar layering (Vieli and others, 2004)', which were calibrated by dating at the intersection with the Vostok ice core. An alternate $A$ of $30 \mathrm{~mm}$ $\mathrm{a}^{-1}$ in the vicinity of Vostok station (also from the compilation of field data only by Giovinetto and Zwally, 2000) gives $\mathrm{d} S_{\mathrm{ns}} /$ $\mathrm{d} t$ of $100 \mathrm{~mm} \mathrm{a}^{-1}$ and $\mathrm{d} h_{\mathrm{gps}} / \mathrm{d} t$ of $+37.9 \mathrm{~mm} \mathrm{a}^{-1}$ (or +28.8 $\mathrm{mm} \mathrm{a}^{-1}$ using $\rho_{\mathrm{ns}}=0.30 \mathrm{~g} \mathrm{~cm}^{-3}$ ).

5. 'Zwally and others (2015) challenge the stability of the GPS markers presented by Richter and others (2014), describing them as "poles placed in the firn to some unspecified depths" and claiming: "An unspecified potential source of error is possible motion of their GPS markers within the firn". Richter and others (2014) state: The markers consist of wooden stakes or aluminum tubes initially emplaced at least $50 \mathrm{~cm}$ deep in the snow.'

Incompressible poles in a compressing medium can have only one point of motion in common. As we noted 'The measured $V_{\text {gps }}$ is intended to be the velocity of firn compaction plus the velocity of the ice beneath the firn.' In the pioneering measurements by lan Whillans and co-workers, exceptional care was taken to secure a well-defined anchor point in the firn (Hamilton and others, 1998), because the velocity of firn compaction varies with depth in the firn as the density increases. Examples of measurements of the depth variation of the vertical strain rate in firn are described in Arthern and others (2010).

'Finally, Richter and others (2014) presented vertical velocities of 56 GNSS markers distributed over the whole lake area.... The velocities range from -50 to $-60 \mathrm{~mm} \mathrm{a}^{-1}$ in the southern part of the lake up to -80 to $-100 \mathrm{~mm} \mathrm{a}^{-1}$ in the northern part....this is a combined effect of a regional $\mathrm{N} / \mathrm{S}$ accumulation gradient, proven independently by glaciological data, and the hydrostatic balance of the floating ice.' It is neither clear what causes their large range of measured velocities at 56 markers, nor how that range of velocities is accounted for by accumulation variations over the Lake. It is also not clear what they assume causes the lowering of their markers as depicted in Fig. 2b of Richter and others (2014) for two reasons: (1) their figure only depicts the portion of the firn densification in the lower part of the pole above the pole base, and does not depict the downward velocity of firn compaction (i.e. $\left.V_{\mathrm{fc}}\left(z_{\text {base }}\right)\right)$ at the pole base due to the greater densification occurring down to the depth of the firn/ ice transition; and (2) their figure does not include the vertical component of ice flow $\left(V_{\text {ice}}\right)$ below the firn (cf. Fig. 2 in Zwally and $\mathrm{Li}, 2002)$. Therefore assuming the pole is anchored at the base, their measured velocity should be $V_{\mathrm{fc}}\left(z_{\text {base }}\right)+V_{\text {ice. }}$. For a comparison of the relative magnitudes of $V_{\mathrm{fc}}(z)$ and $V_{\text {ice }}$ in the steady state, for example, $V_{\mathrm{fc}}(z=0) \approx 2.1 V_{\text {ice }}$ at the surface and the total surface velocity is $V(z=0) \approx 3.1 V_{\text {ice, }}$ where $V_{\text {ice }}=\langle A\rangle / \rho_{\text {i }}$ and $\langle A\rangle$ is the mean surface accumulation (Zwally and Li, 2002). Considering the attention given to one measurement from Richter and others (2008), it would be interesting to see similar specific analysis for the other 56 markers and how their chosen accumulation rates for that large range of measured velocities might indicate a stable surface.

6. 'Based on.... the stability of the ice surface height above Vostok Subglacial Lake....Richter and others (2014) derived relative ICESat intercampaign biases....'.

Intercampaign biases determined over a surface using an incorrect conclusion or assumption that the vertical motion 
of the surface is zero will include a trend in the biases equal to the vertical motion of the surface, which we believe is the case for the biases estimated over Vostok Lake.

\section{ACKNOWLEDGEMENTS}

We very much appreciate the insightful comments and suggestions of an anonymous reviewer, the numerous engineers and scientists dedicated to the success of the ICESat mission, and the continued support of NASA management.

${ }^{1}$ Cryospheric Sciences Laboratory, NASA Goddard Space Flight Center, Greenbelt, MD, USA, ${ }^{2}$ Earth System Science Interdisciplinary Center, University of Maryland, College Park, $M D, U S A,{ }^{3} S G T$, Inc., NASA

Goddard Space Flight Center, Greenbelt, MD, USA, ${ }^{4}$ Craig Technologies, NASA Goddard Space Flight Center, Greenbelt, MD, USA, ${ }^{5}$ Science Systems and Applications, Inc., NASA Goddard Space Flight Center, Greenbelt, MD, USA

${ }^{6}$ Sigma Space Corporation, Lanham, MD, USA

E-mail: H. JAY. ZWALLY<jayzwallyice@verizon.net>

\section{REFERENCES}

Arthern RJ, Vaughan DG, Rankin AM, Mulvaney R and Thomas ER (2010) In situ measurements of Antarctic snow compaction compared with predictions of models. J. Geophys. Res., 115, F03011 (doi: 10.1029/2009JF001306)

Fricker HA and Scambos T (2009) Connected subglacial lake activity on lower Mercer and Whillans ice streams, West Antarctica, 2003-2008. J. Glaciol., 55(190), 303-315

Giovinetto MB and Zwally HJ (2000) Spatial distribution of net surface accumulation on the Antarctic Ice Sheet. Ann. Glaciol., 31, 171-178

Hamilton GS, Whillans IM and Morgan PJ (1998) First point measurements of ice-sheet thickness change in Antarctica. Ann. Glaciol., 27, 125-129

Richter A, Howarth M and Dietrich R (2016) Comment on Mass Gains of the Antarctic Ice Sheet exceed Losses by $\mathrm{H}$. Jay Zwally and others (2015)

Richter A and 9 others (2008) Observational evidence on the stability of the hydroglaciological regime of subglacial Lake Vostok. Geophys. Res. Lett., 35, L11502 (doi: 10.1029/ 2008GL033397)

Richter A and 12 others (2014) Height changes over subglacial Lake Vostok, East Antarctica: insights from GNSS observations. J. Geophys. Res.: Earth Surf., 119, 2460-2480 (doi: 10.1002/ 2014JF003228)

Takahashi S and Kameda T (2007) Instruments and Methods: Snow density for measuring surface mass balance using the stake method. / Glacio., 53(183), 677-678

Vieli GJ-MC, Siegert MJ and Payne AJ (2004) Reconstructing ice sheet accumulation rates at ridge B, East Antarctica. Ann. Glaciol., 39, 326-328 (doi: 10.3189/172756404781814519)

Wingham DJ, Siegert MJ, Shepherd A and Muir AS (2006) Rapid discharge connects Antarctic subglacial lakes. Nature, 440, 1033-1036

Zwally HJ and Li J (2002) Seasonal and interannual variations of firn densification and ice-sheet elevation at $\mathrm{G}$ Greenland summit. J. Glaciol., 48(161), 199-207

Zwally HJ, Li J, Robbins JW, Saba JL, Yi D and Brenner AC (2015) Mass gains of the Antarctic ice sheet exceed losses. J. Glaciol., 61(230), 1019-1035 (doi: 10.3189/2015JoG15J071) 